\title{
8. LOG EVALUATION OF LEG 1 OF THE DEEP SEA DRILLING PROJECT ${ }^{1}$
}

\author{
K. F. Kennedy, H. A. Shillibeer \& C. E. Konen \\ Gulf Research \& Development Company, Houston, Texas
}

\section{Introduction}

The objective of this chapter is to evaluate the well logs that have been run on Leg 1 of the Deep Sea Drilling Project. Since, however, only one complete set of resistivity, gamma-ray, neutron, and qualitative density logs is available, this section will consist of an evaluation of the logs from Site 1.

The use of well logs for evaluating the physical and chemical composition of subsurface formations is a common practice in the petroleum and mining industries. The devices normally utilized for these procedures were designed for larger diameter openings than those used in this project. The size limitation imposed here made it necessary to use a qualitative density measurement rather than a quantitative log.

\section{Evaluation of Log Responses}

Prior to an evaluation of the logs, the curves were digitized and re-recorded as a composite log. The composite log consisted of gamma-ray, resistivity, and density curves.

An attempt was made to establish a density scale in terms of grams per cubic centimeter by using the reported GRAPE (Gamma Ray Attenuation Porosity Evaluator) measurements of bulk density, however, this was not successful. This does not preclude the establishment of a quantitative scale at a later date; if a sufficient number of bulk density measurements become available. It may then be possible to establish a relationship between bulk density and counting rate.

It should be noted that variations in the diameter of the borehole may cause large excursions in the density counting rate. The effects of variation in hole diameter are not restricted to the density measurement

\footnotetext{
${ }^{1}$ Prepared at the request of the JOIDES Advisory Panel on Well Logging in the absence of a specialist in the evaluation of well logs on the permanent staff of the Project.
}

alone. If hole size variations occur, the recorded values of resistivity and natural gamma rays will vary, too. Resistivity and gamma-ray counting rate will also vary with mud resistivity and mud weight, respectively.

The neutron curve which was recorded inside the drill pipe reflects little information about the formations penetrated. The lithological information, if any, is completely obscured by the drill pipe, collars, etc.

The composite log shows a very good correlation between the gamma-ray, resistivity, and density curves. Whether the log responses are only reflecting lithological variations is questionable. The general increase of resistivity and the decrease of density counting rate with depth indicate increasing consolidation. A number of zones, not cored, denote the existance of silt and quartz laminae. These intervals are indicated by low resistivity, high density counting rates and low gamma-ray deflection. The separation of the 16 inch and 64 inch normal curves signifies that invasion of drilling fluid into the formations has occurred. This would suggest that the formations are permeable and have a larger grain size than the surrounding beds.

The gamma-ray curve also shows an increase in natural radioactivity with depth. This could indicate that hole enlargement has occurred in the upper portions of the borehole with a gradual reduction with depth.

\section{Conclusions}

1. The gamma-ray, resistivity, and density logs show definite correlative features.

2. The large excursions of the density log may or may not reflect lithological variations depending upon the constancy of hole diameter. The large variations in counting rate do not necessarily reflect large changes in formation density since a logarithmic function probably relates bulk density and counting rate.

3. When more bulk density data becomes available, it should be possible to calibrate the density log in terms of bulk density. 